\title{
AN EXPERIMENTAL STUDY ON HYDRODYNAMIC CHARACTERISTICS OF GLIDING-HYDROFOIL CRAFT
}

Shu Ling Chen

School of Engineering and Mathematical Sciences, City University, London, UK. Department of Naval Architecture, Jiangsu University of Science and Technology, Zhenjiang, Jiangsu, P.R.C.

Song Lin Yang

Department of Naval Architecture, Jiangsu University of Science and Technology, Zhenjiang, Jiangsu, P.R.C.

Qingwei Ma

School of Engineering and Mathematical Sciences, City University, London, UK., q.ma@city.ac.uk

Follow this and additional works at: https://jmstt.ntou.edu.tw/journal

Part of the Engineering Commons

\section{Recommended Citation}

Chen, Shu Ling; Yang, Song Lin; and Ma, Qingwei (2011) "AN EXPERIMENTAL STUDY ON HYDRODYNAMIC CHARACTERISTICS OF GLIDING-HYDROFOIL CRAFT," Journal of Marine Science and Technology: Vol. 19: Iss. 1, Article 10.

DOI: $10.51400 / 2709-6998.2140$

Available at: https://jmstt.ntou.edu.tw/journal/vol19/iss1/10

This Research Article is brought to you for free and open access by Journal of Marine Science and Technology. It has been accepted for inclusion in Journal of Marine Science and Technology by an authorized editor of Journal of Marine Science and Technology. 


\section{AN EXPERIMENTAL STUDY ON HYDRODYNAMIC CHARACTERISTICS OF GLIDING-HYDROFOIL CRAFT}

Acknowledgements

This work is partially sponsored by the UK Royal Society, for which the authors are grateful. 


\title{
AN EXPERIMENTAL STUDY ON HYDRODYNAMIC CHARACTERISTICS OF GLIDING-HYDROFOIL CRAFT
}

\author{
Shu Ling Chen****, Song Lin Yang**, and Qingwei Ma*
}

Key words: gliding-hydrofoil craft (GHC), hydrodynamics, model tests, experimental study, hydrodynamic characteristics.

\begin{abstract}
The Gliding-Hydrofoil Craft (GHC) has been recently proposed by the authors from JUST, which is partially similar to a planing craft but has a hydrofoil installed in the front part of the ship. To study its hydrodynamic characteristics, model tests are carried out in a towing tank, and the total resistance, trim angle and wetted area of the craft in the cases with different Froude numbers are measured. This paper presents analysis on the experimental data and discusses the effects of the submerged depth and initial attack angle of the hydrofoil.
\end{abstract}

\section{INTRODUCTION}

As development of the marine transportation, there is an increasing demand on high-speed craft. Many types of highspeed craft have been proposed. Two of them have attracted particular interests. They are planing craft and hydrofoil craft. The former has specially-designed bottom form, which produces hydrodynamic forces in vertical direction to lift the vessel during cruise at a high speed and so resistance on the craft is relatively smaller compared with conventional displacement ships. Its disadvantage, however, lies in its bad seakeeping properties and potentially significant speed losses due to serious pounding or slamming in waves [26]. The latter is hydrofoil vessels that have tow hydrofoils installed in fore and aft parts. The foils may lift the main hull outside water and so the vessels have a very small wetted area during cruise at a high speed. Their performance in terms of speeds is even better than the planing craft. However, a sophisticated control system may be required to stabilize the motion of the hydrofoil craft and to improve their maneuverability $[3,11,21]$. In addi-

Paper submitted 11/09/09; revised 14/01/10; accepted 15/01/10. Author for correspondence: Qingwei Ma (e-mail: q.ma@city.ac.uk).

*School of Engineering and Mathematical Sciences, City University, London, UK.

**Department of Naval Architecture, Jiangsu University of Science and Technology, Zhenjiang, Jiangsu, P.R.C. tion, it has also been reported that a cresting and foil exposing may occur in following seas $[13,15,16]$. In order to take the advantages of these two types of craft and minimize their disadvantages, the gliding-hydrofoil craft (GHC) was proposed by Yang and Gao [24]. This craft distinguishes from the planing craft by a hydrofoil mounted on the front part of the vessel. The hydrofoil provides a lift force on the hull and helps reduce the possibility of pounding or slamming. Unlike the hydrofoil craft, the stern part of the GHC remains in the water at the cruise speed and so its maneuverability is potentially better than the hydrofoil craft. Our preliminary studies $[24,25]$ have shown its superiority over the traditional planing craft.

The experimental studies or model tests for planing and hydrofoil craft have been carried out for decades. Many publications associated with them have been reported. Only some are mentioned here as examples. For planing craft, Clement and Blount [6] conducted an extensive model tests on a systematic series (Series 62). Savitsky [18] developed regression formulas for estimating the hydrodynamic forces acting on planing craft. Savitsky et al. [19] investigated the characteristics of the wetted bottom area and the spray area. As for the hydrofoil craft, Henry et al. [10], Besch and Liu [2] and Abramson [1] studied the flutter of hydrofoil vessels. Inukai et al. [12] tested a sailing catamaran with submerged foils. Kim et al. [13] carried out experiments to study the longitudinal motion of a fully submerged hydrofoil craft in following sea.

Apart from experimental studies, many researchers have also carried out numerical simulations. They have studied, for instance, vortex distribution $[14,17,22]$ and pressure distribution $[5,7,9,20]$. More details about research on the hydrodynamics of the planing and hydrofoil craft may be found in Faltinsen [8].

Due to its distinctive structure, the hydrodynamic characteristics of the GHC are different from either the planing craft or hydrofoil craft and needs to be extensively studied. For this purpose, Yang and Gao [24] carried out experiments on a 1.58 $\mathrm{m}$ GHC ship model in a river and measured the ratio of resistance to the weight of the craft at different speeds and gave a curve relating effective power to its speeds. Yang and Chen [23] investigated the interaction between the navigation speed of the craft and the rotational speed of its main engine, again 


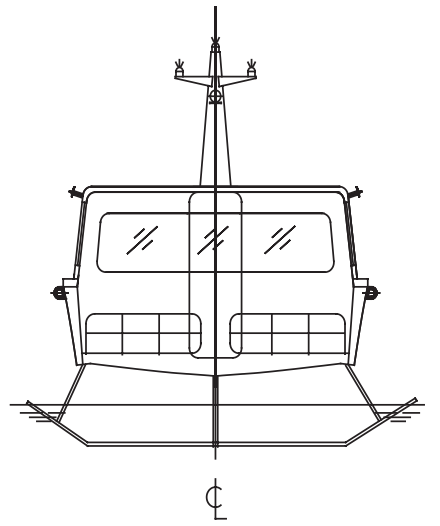

(a)

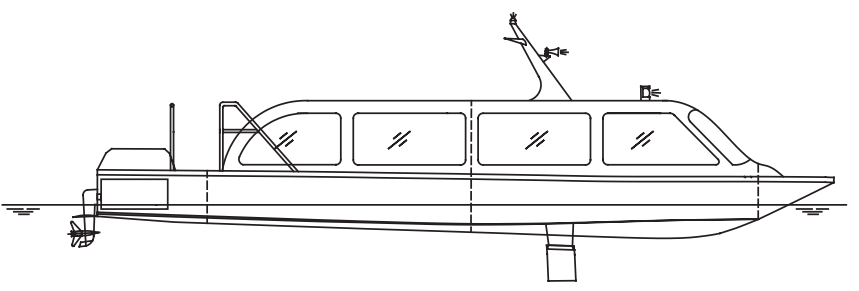

(b)

Fig. 1. The sketch of the GHC. (a) Front view of the GHC, (b) Side view of the GHC.

based on the model test in a river. Yang et al. [25] started to experimentally study the hydrodynamics of the GHC, but only gave some preliminary analysis for some cases at several speeds. Chen et al. [4] also carried out some experimental studies on the hydrodynamics of the GHC, but a very simple rectangular hydrofoil section was used.

This paper will further consider the hydrodynamic characteristics of the GHC based on the model tests in a towing tank carried out very recently. The resistance, trim angle and wetted area at different forward speeds will be analyzed and discussed in a more robust way.

\section{THE GHC MODEL}

As indicated above, the GHC is similar to a planing hull but with a hydrofoil in the front part of its body. A sketch of the GHC is shown in Fig. 1. The model used in the tests is largely similar to the one in Fig. 1, but relatively simple. The principal parameters, including length, breath, draft, weight and so on, of the model, are detailed in Table 1. The body plan of the model is shown in Fig. 2, in which one can see the perimeter of the cross-section at each of the stations (numbered as $0-10$ in the figure).

A TV-shaped hydrofoil is mounted at a position about $0.43 \mathrm{~m}$ from the bow. The cross-section of the hydrofoil is chosen to be arch-shaped, as shown in Fig. 3. Figure 4 shows a photo of the model. The model is made of wood, fiberglass and plastic. The hydrofoil is made of aluminum. The frame is made of stainless steel. During the tests, the board with a
Table 1. Principal parameters of the GHC model.

\begin{tabular}{|c|c|}
\hline Length $(\mathrm{m})$ & 1.18 \\
\hline Breadth $(\mathrm{m})$ & 0.35 \\
\hline Draft $(\mathrm{m})$ & 0.07 \\
\hline Initial wetted length $L_{S}(\mathrm{~m})$ & 1.12 \\
\hline Initial wetted area $S_{S}\left(\mathrm{~m}^{2}\right)$ & 0.413 \\
\hline Weight $(\mathrm{kg})$ & 8.144 \\
\hline Foil arrangement & 0.43 m from the bow \\
\hline Foil type & arch section \\
\hline Foil chord $(\mathrm{mm})$ & 44 \\
\hline Foil Span $(\mathrm{mm})$ & 390 \\
\hline
\end{tabular}

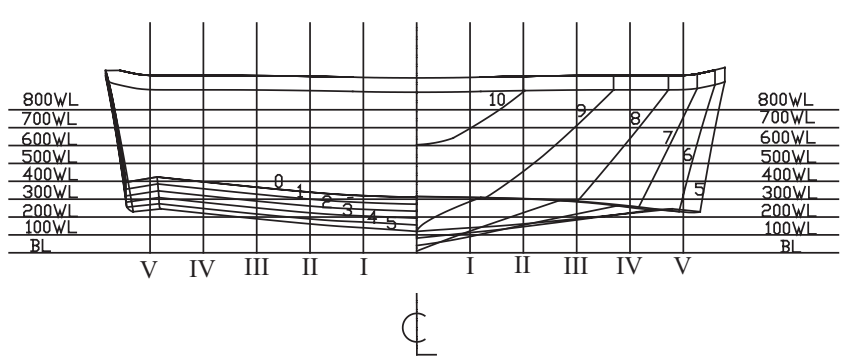

Fig. 2. The body plan of the GHC.
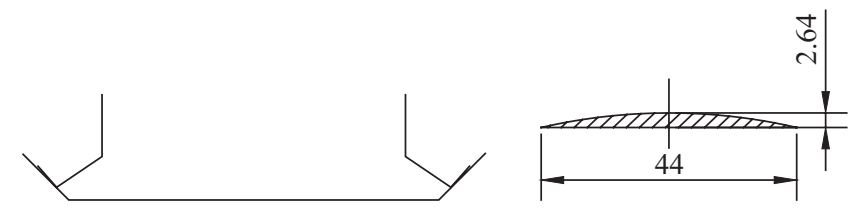

(a)

(b)

Fig. 3. (a) The front view of the TV-shaped hydrofoil and (b) the cross section of the hydrofoil.

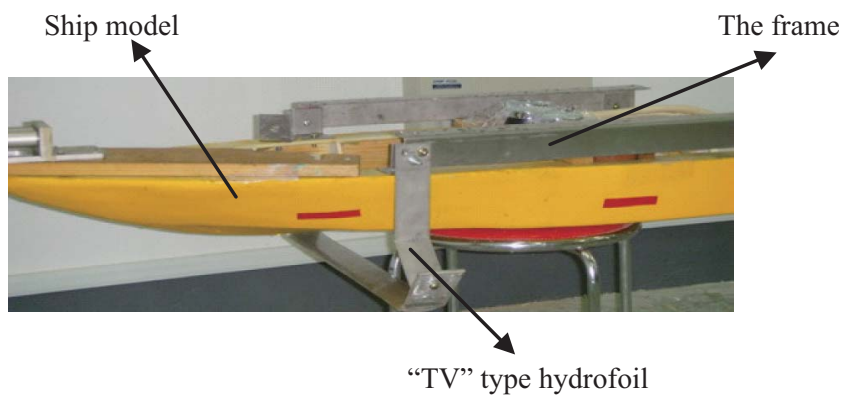

Fig. 4. The GHC model.

height of $80 \mathrm{~mm}$ is fixed on the edge of the upper deck to prevent water from spraying on the deck.

\section{EXPERIMENTAL METHODS}

\section{The Towing Tank}

The model tests are carried out in the towing tank at Jiangsu 
Table 2. Test Cases.

\begin{tabular}{|c|c|c|c|c|c|c|c|c|c|c|c|c|}
\hline \multirow{2}{*}{ Ship model } & \multirow{2}{*}{$\begin{array}{c}\text { Initial attack angle } \\
\text { of hydrofoil }\end{array}$} & \multirow{2}{*}{$\begin{array}{l}\text { Submerged depth } \\
\text { of hydrofoil }\end{array}$} & \multirow{2}{*}{$\begin{array}{l}\text { Case } \\
\text { No. }\end{array}$} & \multicolumn{9}{|c|}{ Towing speed $(\mathrm{m} / \mathrm{s})$} \\
\hline & & & & 1.7 & 2.04 & 2.38 & 2.72 & 3.06 & 3.4 & 3.74 & 4.08 & 4.39 \\
\hline Planing Craft & N/A & N/A & V0 & $\sqrt{ }$ & $\sqrt{ }$ & $\sqrt{ }$ & $\sqrt{ }$ & $\sqrt{ }$ & $\sqrt{ }$ & $\sqrt{ }$ & $\sqrt{ }$ & $\sqrt{ }$ \\
\hline \multirow{6}{*}{$\begin{array}{l}\text { Gliding-hydrofoil } \\
\text { craft }\end{array}$} & 0 degree & $40 \mathrm{~mm}$ & $\mathrm{I} 1$ & $\sqrt{ }$ & $\sqrt{ }$ & $\sqrt{ }$ & $\sqrt{ }$ & $\sqrt{ }$ & $\sqrt{ }$ & $\sqrt{ }$ & $\sqrt{ }$ & $\sqrt{ }$ \\
\hline & 0 degree & $50 \mathrm{~mm}$ & $\mathrm{I} 2$ & $\sqrt{ }$ & $\sqrt{ }$ & $\sqrt{ }$ & $\sqrt{ }$ & $\sqrt{ }$ & $\sqrt{ }$ & $\sqrt{ }$ & $\sqrt{ }$ & $\sqrt{ }$ \\
\hline & 0 degree & $60 \mathrm{~mm}$ & $\mathrm{I} 3$ & & & $\sqrt{ }$ & $\sqrt{ }$ & $\sqrt{ }$ & $\sqrt{ }$ & $\sqrt{ }$ & $\sqrt{ }$ & $\sqrt{ }$ \\
\hline & -2 degree & $40 \mathrm{~mm}$ & I4 & & & $\sqrt{ }$ & $\sqrt{ }$ & $\sqrt{ }$ & $\sqrt{ }$ & $\sqrt{ }$ & $\sqrt{ }$ & $\sqrt{ }$ \\
\hline & -2 degree & $50 \mathrm{~mm}$ & I5 & & & $\sqrt{ }$ & $\sqrt{ }$ & $\sqrt{ }$ & $\sqrt{ }$ & $\sqrt{ }$ & $\sqrt{ }$ & $\sqrt{ }$ \\
\hline & -2 degree & $60 \mathrm{~mm}$ & I6 & & & $\sqrt{ }$ & $\sqrt{ }$ & $\sqrt{ }$ & $\sqrt{ }$ & $\sqrt{ }$ & $\sqrt{ }$ & $\sqrt{ }$ \\
\hline
\end{tabular}

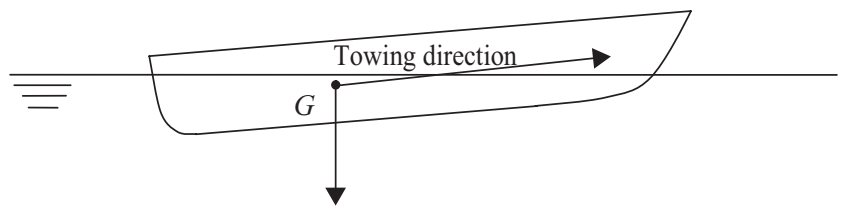

Fig. 5. Towing method in the tests.

University of Science and Technology. The length $(L)$, width $(W)$ and depth $(D)$ of the tank are $100 \mathrm{~m}, 6 \mathrm{~m}$ and $2.5 \mathrm{~m}$, respectively. The water depth in the working area is about $2.0 \mathrm{~m}$. During experiments, the humidity of the laboratory is about $70 \%$ and the water temperature is about $20^{\circ} \mathrm{C}$. A carriage is installed with the tank to tow the ship model properly. The speed of the carriage and towing distance are controlled by a computer. The errors are within a range of $\pm 0.1 \%$. The force measurement instrument is equipped with the carriage to measure the resistance of the GHC model. The fore and aft drafts are also measured by using the sensors mounted on the carriage for calculating the trim angle and wetted area.

\section{Experimental Techniques}

To perform the model tests on the GHC, we need to adjust its initial attitude and to determine the towing method. The details are given as follows.

\section{1) Adjust the Attitude of the Model}

Based on our previous research work, it is recognized that the initial trim angle of the GHC is not necessarily set as zero to achieve desired states. In the tests discussed in this paper, the initial trim angle of the model is set as -2 degree (a positive trim angle means that the bow is upward or vise versa). To achieve this, the ballast is used and its position is determined by a trial-and-error method. After doing so, the initial values of the fore and aft drafts are recorded.

\section{2) Towing Method}

In this study, the ship model is towed through the gravity centre of the model and the towing line is roughly parallel to the deck at start (Fig. 5). In this method, the model moves freely in vertical direction, i.e., freely heaving and pitching. In addition, the vertical position of the gravity center after the model motion becomes steady at a speed may be higher than its initial one due to hydrodynamic lift forces acting on the foil and on the planing hull. Nevertheless, we can only measure the tension force acting on the towing line because of the limitation of our test facility. This force is not the same as the resistant force but can be considered as a good approximation to the latter. That is because the real angle of the towing line with respect to the horizontal direction is very small, typically much less than 10 degree.

\section{Test Cases}

Hydrodynamic characteristics of the model are affected by several parameters, such as the initial attack angle and submerged depth of the hydrofoil and towing speeds. Various cases are considered in the tests to study their effects. Table 2 gives the values of the parameters for all the cases.

\section{Measured Data and Post-Processing}

In the model tests, the tension forces on the towing line as well as the fore and aft drafts are directly measured for the cases given in Table 2. To post-process the data, several dimensionless parameters are defined as follows. Two of them are the Froude number $\left(F r_{s}\right)$ and Reynolds number $\left(\operatorname{Re}_{s}\right)$, which are given, respectively, by

$$
F r_{S}=U_{\mathrm{C}} / \sqrt{g L_{w}}
$$

and

$$
R e_{S}=U_{c} L_{w} / v
$$

where, $U_{c}$ is the towing speed, $L_{w}$ is the wetted length of the ship model corresponding to the towing speed $\left(L_{w}\right.$ is called as corresponding wetted length in this paper and the dimensionless parameters based on it will be called as corresponding Froude number and Reynolds number respectively) and $v$ is the kinematic viscosity coefficient of water. Apart from the above definitions, the Froude and Reynolds numbers may also be defined in terms of the initial wetted length. Since the corresponding length of the GHC at a towing speed is gener- 


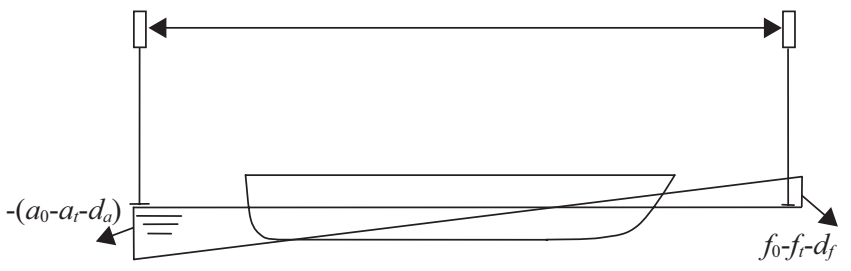

Fig. 6. Illustration of the method for estimating the trim angle.

ally different from the initial wetted length, these parameters based on the initial wetted length generally have different values from the former. The two kinds of definitions may be employed for different purposes. When considering the hydrodynamic properties, these based on the corresponding wetted length are preferred. However, before the model tests are run, the corresponding wetted length of the model is unknown, and thus the Froude and Reynolds numbers based on the initial wetted length are more convenient to use.

In addition to the above two dimensionless parameters, the resistance $\left(R_{t}\right)$ is also expressed in a dimensionless form as:

$$
C_{d}=\frac{R_{t}}{\frac{1}{2} \rho U_{C}^{2} S}
$$

where $\rho$ is the density of water and $S$ is the wetted area of the model at the corresponding speed.

As indicated above, the fore and aft drafts are measured in tests. Using them, we can calculate the trim angle $(\theta)$ by

$$
\operatorname{tg} \theta=\frac{\left(f_{0}-f_{t}\right)-\left(a_{0}-a_{t}\right)-\left(d_{f}-d_{a}\right)}{l}
$$

where, $f_{0}$ and $f_{t}$ are the reading of the fore sensor at start and in the steady state for a specified speed; $a_{0}$ and $a_{t}$ are their counterpart but from the aft sensor; $d_{f}$ and $d_{a}$ are the initial fore and aft drafts, respectively; and $l$ the distance between the two sensors, as shown in Fig. 6.

In addition to the trim angle, the data measured at the two sensors can also help us to determine the water line corresponding to the trim angle. With this water line, we can get the corresponding wetted length. Combining the water line with the body plan (Fig. 2), one can estimate the wetted perimeter $(\Gamma(x))$ of the immersed cross-section at each of the stations. Based on these, the wetted area of the GHC at the speed can be obtained by:

$$
A=\sum_{j} \Gamma\left(x_{j}\right) \Delta x_{j}
$$

where, $\Delta x_{j}$ is the distance between two successive stations.

It is noted that the wave profile along the hull surface varies depending on hull and speed, and on if spray occurs. Direct measurement of the wetted area is not easy. When estimating

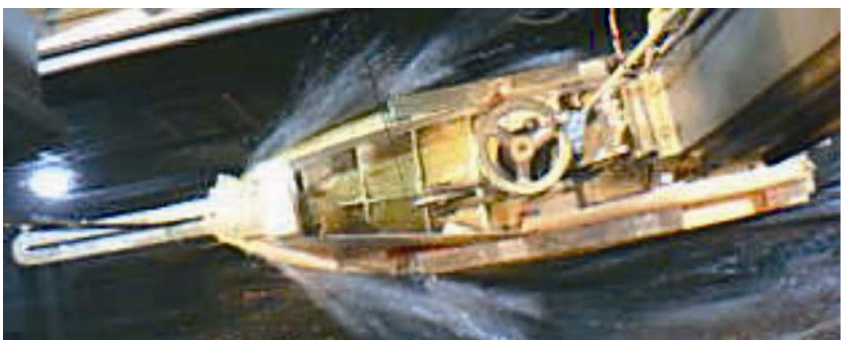

Fig. 7. A photo of wave patterns around the model during experiment in the towing tank.

the wetted hull surface area using Eq. (5), these factors are ignored and so the wetted area obtained in this way is an approximation. Nevertheless, the approximation can be considered as to reasonably reflect the main features of the wetted area.

In all the tests, a digital camera is mounted on the carriage to record wave patterns around the model. One of examples is shown in Fig. 7. Our attention will be focused on the quantitative analysis on the experimental data in the paper, more discussion about the photos will not be given.

\section{RESULTS AND DISCUSSIONS}

In the rest of the paper, we will mainly discuss the hydrodynamics characteristics of the GHC according to the data measured in the tests, which include the trim angle and corresponding resistance.

\section{Hydrodynamic Characteristics Corresponding to Different Froude and Reynolds Numbers}

As mentioned above, the corresponding wetted length and area are different for different speeds and thus the corresponding Froude number and Reynolds number are different from those based on the initial wetted length. It is interesting to see how they change with the Froude number based on the initial length $\left(F_{r}=U_{c} / \sqrt{g L_{s}}\right.$, where $L_{s}$ is the initial wetted length). Figure 8 shows the corresponding wetted length and wetted area for Case I 2 while Fig. 9 presents the corresponding Froude and Reynolds numbers for the same case. It can be seen from Fig. 8 that the corresponding wetted length and area looks unchanged in the range of $F_{r}<0.8$ or $F_{r}>1.0$, though their values are different in the different ranges. In the range of $F_{r}<0.8$, the wetted length and area are almost the same as the initial ones. This indicates that the trim angle is very small and the lift force acting on the hydrofoil may not be large enough to lift the model up, which is expected. On the other hand, the wetted length and area remain to be almost constant but much smaller compared with their initial values in the range $F_{r}>1.0$. This implies that the trim angle and lift force on the foil do not significantly vary with the increase of the speeds under the condition. It is also seen from Fig. 8 that the reduction of the corresponding length and area are quite rapid 


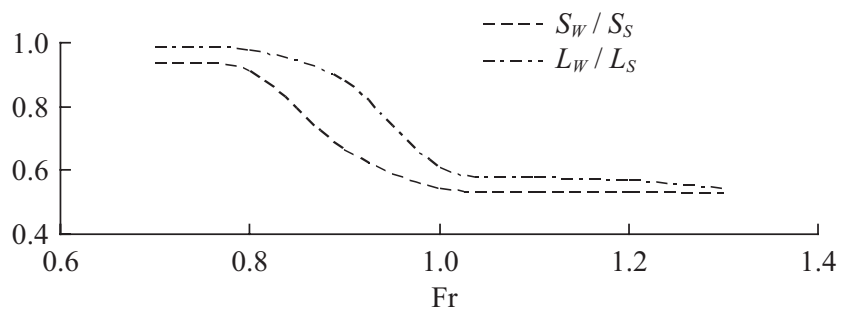

Fig. 8. Wetted length and area in Case $I 2\left(F_{r}=U_{c} / \sqrt{g L_{s}}\right)$.

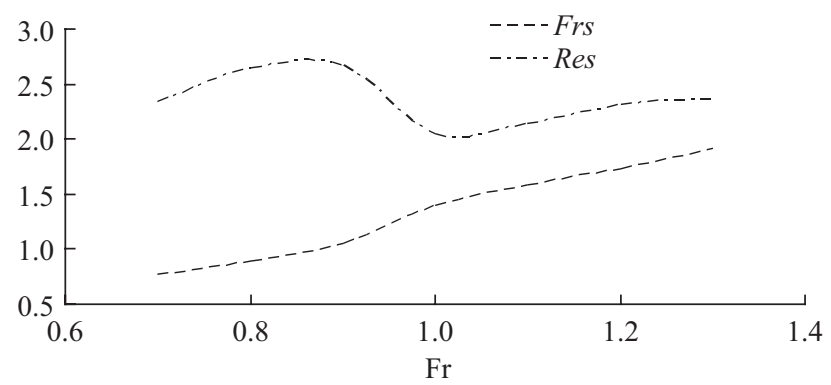

Fig. 9. Corresponding Froude and Reynolds numbers against the Froude number based on the initial length in Case $\mathbf{I}\left(F_{r}=U_{c} / \sqrt{g L_{s}}\right)$.

in the range of $0.8<F_{r}<1.0$, indicating that the trim angle and the lift force on the foil increase quite rapidly with the increase of speeds in this range. If looking at Fig. 9, it is found that the corresponding Froude number always increases with the increase of speeds, though the rate is different, while there is a reduction in the corresponding Reynolds number between $0.9<F_{r}<1.0$. The latter phenomenon indicates that the rate of the reduction in the wetted length is more rapid than the increase of the speed in this range.

Next, let us look at how the resistance coefficient and trim angle changes with the change of the corresponding Froude and Reynolds numbers for Case I2, in which the initial attack angle and the submerged depth of the hydrofoil are $0^{\circ}$ and $50 \mathrm{~mm}$, respectively. Figure 10 and Fig. 11 give the corresponding results.

As has been deduced, the trim angle is very small for small Froude number and its rate of change is very low when the Froude number is large (Fig. 10). Only in the moderate values of the Froude number ( 0.8 to 1.4$)$, it changes significantly from $-2^{\circ}$ to $6^{\circ}$. When $\mathrm{Fr}_{s}$ is larger than 1.4, the trim angle is almost a constant $\left(\right.$ about $6^{\circ}$ ). Figure 11 displays the resistance coefficient. From this figure, it is observed that the resistance coefficient has a rapid change in the range of $F r_{s} \approx 0.8$ to 1.4, in which the trim angle increase rapidly. After that, the resistance constantly decreases. In this case, the Reynolds number increases to its peak value (about $3.0 \times 10^{6}$ ) and then has a rapid reduction similar to what has been observed in Fig. 9. Thereafter, it increases again as $F r_{s}$ increases but very slowly. It is interesting to note that although the value of Reynolds number at the smallest Froude number in Fig. 11 is roughly the

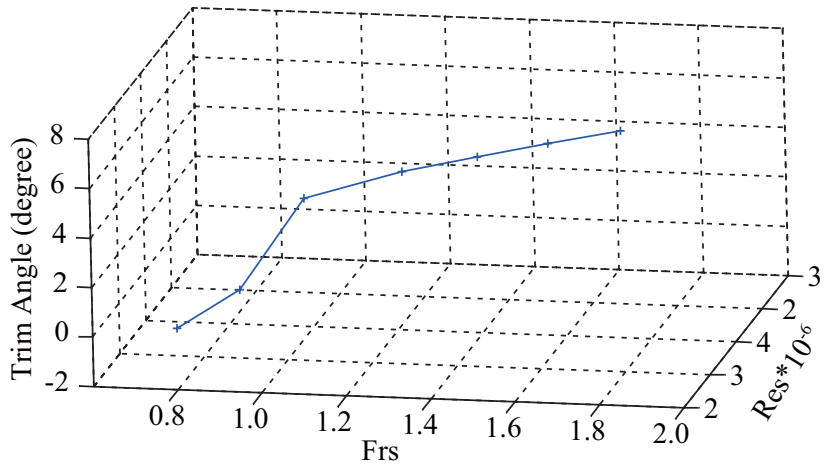

Fig. 10. The Trim angle of GHC (Case I2: initial attack angle of the hydrofoil: $0^{\circ}$, its submerged depth: $50 \mathrm{~mm}$ ).

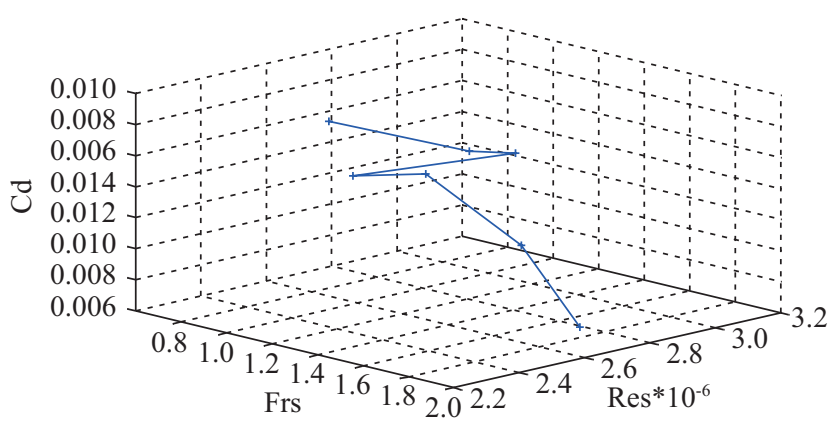

Fig. 11. The resistance coefficient of the GHC (Case I2: initial attack angle of the hydrofoil: $0^{\circ}$; its submerged depth: $50 \mathrm{~mm}$ ).

same as that at the largest Froude number, the resistance coefficient is considerably different. This indicates that the same value of Reynolds number may correspond to different values of the resistance coefficient and thus it may not be appropriate to use the Reynolds number as the unique dimensionless control number in design of prototype GHCs and model tests. Further research is required to understand the correlation between the Reynolds number and the resistance coefficient.

\section{Effect of Submerged Depth of The Hydrofoil}

To analyze the effect of the submerged depth of the hydrofoil, Case I1, Case I2 and Case I3 are considered and the corresponding results are depicted in Fig. 12 and Fig. 13.

Figure 12 displays the trim angle against the corresponding Froude number for the cases with different submerged depth of the hydrofoil. This figure shows that for all the submerged depths, the trim angle increases as the Froude number increases but the rate of the increase is very low when the Froude number is large enough. In addition, the trim angle in Case I2 (submerged depth $=50 \mathrm{~mm}$ ) is smaller than others in the whole range of the Froude number tested. More specifically, the trim angle in Case I 2 is much smaller from those in other two cases in the ranges of $F r_{s}<1$ and $F r_{s}>1.4$, while the trim angles in the range of $1<F r_{s}<1.4$ are very close to those of Case I1 (submerged depth $=40 \mathrm{~mm}$ ). 


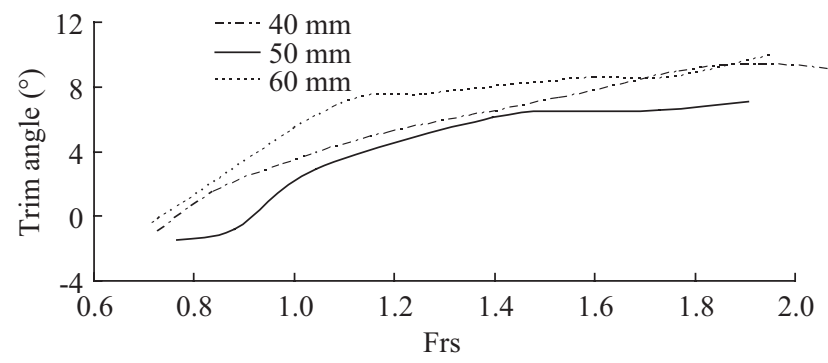

Fig. 12. Trim angles in Case I1, Case $I 2$ and Case $I 3$ (initial attack angle of the hydrofoil: $0^{\circ}$ ).

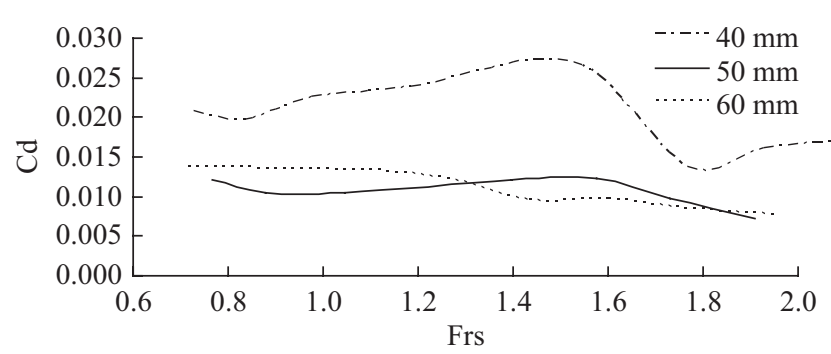

Fig. 13. Drag coefficients in Case I1, Case $I 2$ and Case I3 (initial attack angle of the hydrofoil: $0^{\circ}$ ).

Figure 13 presents the resistance coefficients for these cases. One may see from this figure that the resistance coefficient for Case I1 is considerably larger than those in other two cases. In addition, the coefficient for this case reaches its peak value at $F r_{s} \approx 1.5$ and then decrease rapidly. This phenomenon is not evident in other two cases.

The resistance of the GHC consists of the drag forces on the main hull and on the hydrofoil. The drag force on the main hull largely depends on the trim angle and wetted area but the force on the foil is affected by its submerged depth or by the free surface in other words. The closer the hydrofoil is to the free surface, the larger the wave induced by the foil should be and therefore the larger drag force on it. This may partially explain the phenomenon observed above figures where the large submerged depths correspond to smaller resistance. However, there are other factors affecting the properties and the characteristics of the submerged depth effect may exhibit different features from what are seen here if other parameters are changed. This will be demonstrated in the following figures.

Let us consider Case I4, Case I5 and Case I6. The difference of these three cases from the previous three cases is due to the initial attack angle of the hydrofoil, which is $-2^{\circ}$ here rather than $0^{\circ}$. Figure 14 and Fig. 15 present the trim angles and resistance coefficients for these cases.

It is found from Fig. 14 that the largest trim angle occurs to the submerged depth of $40 \mathrm{~mm}$ when $F r_{s}<1.7$. This is different from that shown in Fig. 12 where the deeper submerged depth, i.e. $60 \mathrm{~mm}$, results in the largest trim angle when $F r_{s}<$ 1.7. In addition, it is also found that when the submerged depth is $50 \mathrm{~mm}$, the corresponding trim angle is the smallest if

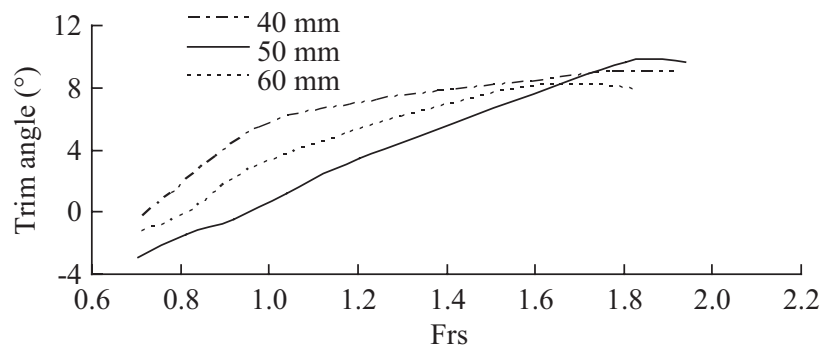

Fig. 14. Trim angles in Case I4, Case $I 5$ and Case I6 (initial attack angle of the hydrofoil: $-2^{\circ}$ ).

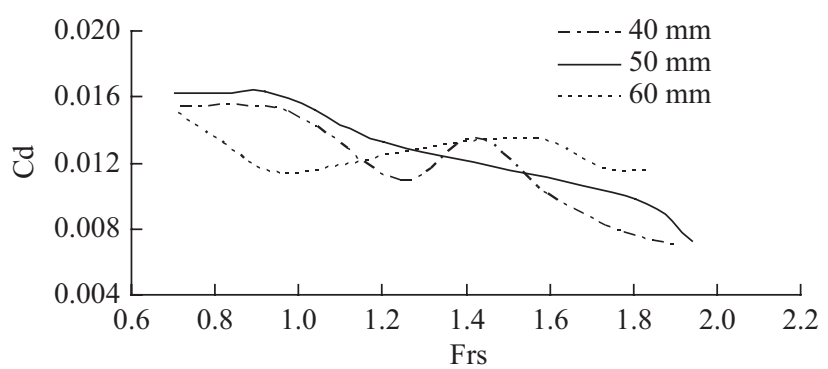

Fig. 15. Drag coefficients in Case I4, Case I5 and Case I6 (initial attack angle of the hydrofoil: $-2^{\circ}$ ).

$F r_{s}<1.7$. When $F r_{s} \approx 1.7$, the trim angles for all the three cases are close to $8^{\circ}$. Looking at Fig. 15, we see that the variations of the resistance coefficients are more complex than those in Fig. 13. There is no case in which the resistance coefficient is always larger than others in the whole range of Froude number tested. Nevertheless, the coefficient for Case I4 (submerged depth $=40 \mathrm{~mm}$ ) is smaller than those in other two cases when $F r_{s}>1.7$. This is opposite to what have been seen in Fig. 13 where the resistance coefficient for the submerged depth of $40 \mathrm{~mm}$ is significantly larger. This complexity indicates that the further research is required to fully understand the hydrodynamics of the GHC.

\section{Effect of the Initial Attack Angles of the Hydrofoil}

To further examine the effect of the initial attack angle of the hydrofoil, the data for Case I 2 and Case I5 are compared in this subsection. Both the cases have the same submerged depth of $50 \mathrm{~mm}$ but different initial attack angles of the hydrofoil.

Figure 16 depicts the comparison of the trim angles for the two cases. From this figure, it is observed that when $F r_{s}<1.5$ (Point $\mathrm{A}$ in the figure), a initial attack angle $\left(0^{\circ}\right)$ leads to relatively larger trim angle but when $F r_{s}>1.5$, it is opposite. On the other hand, the resistance coefficient for the initial attack angle of $0^{\circ}$, presented in Fig. 17, is smaller at the both ends than that for the initial attack angle of $-2^{\circ}$ but reaches a maximum value near $F r_{s}=1.5$ while there is no a maximum value for the latter case. The fact we see here can only indicate that the hydrodynamic characteristics of the GHC is sensitive to the initial attack angle of the hydrofoil. More work is required to draw general conclusion. 


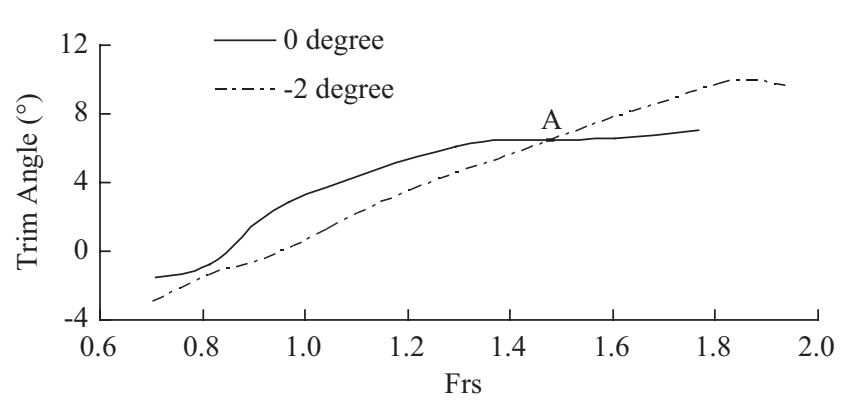

Fig. 16. Comparison of trim angles for Case $I 2$ and Case $I 5$ (submerged depth of the hydrofoil: $50 \mathrm{~mm}$ ).

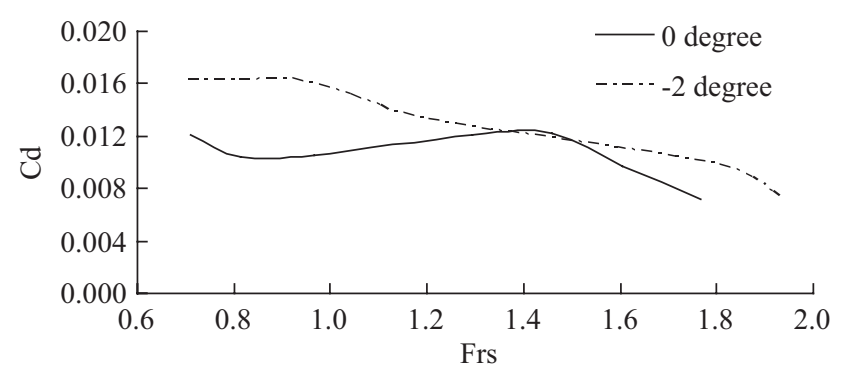

Fig. 17. Comparison of the resistance coefficients for Case $I 2$ and Case I5 (submerged depth of the hydrofoil: $50 \mathrm{~mm}$ ).

\section{Effect of the Hydrofoil}

As discussed in the Introduction, our previous studies have shown superiority of the GHC over the planing craft. In this section, it will be further discussed from the point of view of hydrodynamic properties. For this purpose, another experiment similar to those shown in Figs. 12-17 is carried out. In the experiment, the hydrofoil is removed and thus the model becomes a traditional planing craft (but its initial trim angle is set to be 1 degree, different from the GHC, for the planing craft to gain a final trim angle in a relatively shorter running distance). For the purpose of comparison, Case I2 for the GHC with the submerged depth of $50 \mathrm{~mm}$ and the initial attack angle of hydrofoil $0^{\circ}$ is considered here. In addition, to study the properties of the craft at corresponding speeds, the Froude number based on the initial wetted length is employed.

Figure 18 shows the comparison between the resistance coefficients of the GHC model and the planing craft model. An important feature can be found from this figure, that is, when $F r>1.3$ the resistance coefficient of the GHC is smaller than that of the planing craft. In other words, at a high speed, the GHC has a better performance for a given power or it requires less power to achieve the same speed.

Figure 19 shows the comparison of the trim angles for the same cases in Fig. 18. It can be seen from this figure that the trim angle for the GHC increases rapidly until $F r=1$. When $F r>1$, its trim angle largely remains to be a constant. On the other hand, the trim angle of the planing craft increases in the range of $F r<1.3$ but decreases after that value with the increase of Fr. That implies that the trim angle may go up or

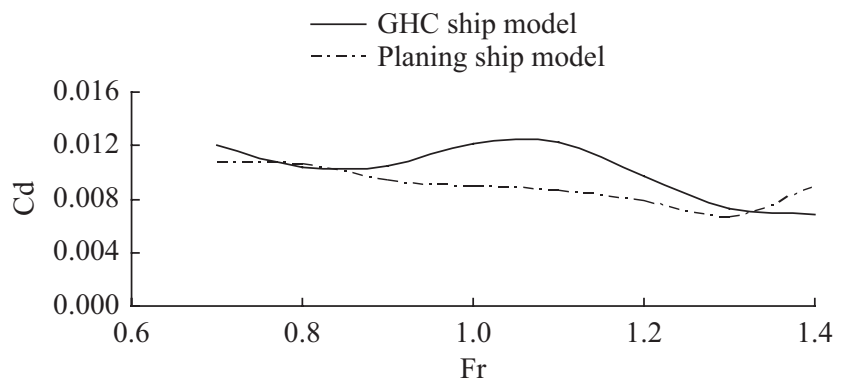

Fig. 18. Comparison between the resistance coefficients of the GHC in Case $I 2$ and the planing craft.

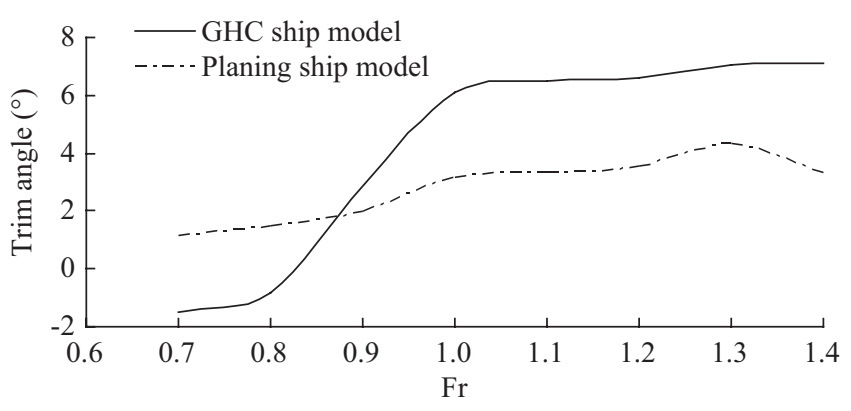

Fig. 19. Comparison between trim angles of the GHC and the planing craft.

down when the velocity changes even due to small increments during real operations. This is consistent with the study by Zhou (2003), which revealed a serious pounding problem of the planing craft. To be contrast, the trim angle of the GHC does not vary significantly in a quite large range of the Froude number as mentioned above and so the serious pounding problem may not appear to the GHC.

According to the discussions above on the two figures, one may see that the GHC may be superior to the planing craft in two aspects: (1) being subjected to relative smaller resistance and (2) unlikely suffering from the serious pounding problem as long as the Froude number is large enough. This is the reason why the GHC was developed. Of course, whether the GHC has a better performance than the planing craft depends on the design and choice of parameters. Nevertheless, this comparison demonstrates that as long as the parameters for the GHC are appropriate, its performance can be superior to the planing craft.

\section{CONCLUSIONS}

This paper has presented the experimental studies on the hydrodynamic characteristics of a GHC model. The resistance, trim angle and the wetted area/length at different forward speeds have been discussed. The results indicated that the wetted area/length and the trim angle of the GHC may significantly change with its speed when the Froude number is relatively small, while they may remain almost unchanged 
when the Froude number is large enough. This implies that the GHC unlikely suffers from the pounding problems under such a condition, which may be always with planing craft. In addition, if the submerged depth and initial attack angle of the hydrofoil are appropriate the resistance coefficient of the GHC may be smaller than the planing craft at a high speed.

Although we have carried out the experiments on many cases, we feel that further research work is required to draw more general conclusion on the hydrodynamic characteristics of the GHC, such as more experimental work for the cases with other initial trim angles. Nevertheless, the experimental data presented in this paper will be very useful for validation of numerical analysis that is easier, less expensive and subjected to less limitation but also very challenging for this kind of the craft.

\section{ACKNOWLEDGMENTS}

This work is partially sponsored by the UK Royal Society, for which the authors are grateful.

\section{REFERENCES}

1. Abramson, N., "Structural dynamics of advanced marine vehicles," In: International Symposium: Dynamics of Marine Vehicles and Structures in Waves, University College London, pp. 344-357 (1974).

2. Besch, P. K. and Liu, Y. N., "Bending flutter and torsional flutter of flexible hydrofoil structs," Proceeding of the Ninth Symposium on Naval Hydrodynamics, Vol. 1, pp. 343-400 (1972).

3. Brown, D. K., Catchpole, J. P., Chem, M. I., and Shand, A. M. J., "An evaluation of the hydrofoil HMS speedy," Transactions of the Royal Institution of Naval Architects, Vol. 126, pp. 1-16 (1984).

4. Chen, S. L., Ma, Q. W. and Yang, S. L., "Preliminary study on hydrodynamics of gliding hydrofoil craft," Advanced Maritime Engineering Conference (AMEC 2008), Chiba, Japan, pp. 639-644 (2008).

5. Cheng, X. and Wellicome, J. F., "Study of planing hydrodynamics using strips of transversely variable pressure," Journal of Ship Research, Vol. 38, pp. 30-41 (1994).

6. Clement, E. P. and Blount, D. L., "Resistance tests of systematic series of planing hull forms," SNAME Transactions, Vol. 71, pp. 491-579 (1963)

7. Doctors, L. J., "Representation of three dimensional planing surfaces by finite elements," Proceedings of the First Conference on Numerical Ship Hydrodynamics, Bethesda, Maryland, pp. 517-537 (1975).

8. Faltinsen, O. M., Hydrodynamics of High-Speed Marine Vehicles, Cambridge University Press, New York (2005).

9. Hassan, G. and Mahmoud, G., "A combined method for the hydrodynamic characteristics of planing crafts," Ocean Engineering, Vol. 35, pp. 310-322 (2008).
10. Henry, C. J., Dugundji, J., and Ashley, H., “Aeroelastic stability of lifting surface in high-density fluids," Journal of Ship Research, Vol. 2, pp. 1021 (1959).

11. Imamura, H., Saito, Y., and Asao, M., "Automatic control system for jetfoil," Kawasaki Technical Review, Vol. 107, pp. 1-9 (1990).

12. Inukai, Y., Horiuchi, K., Kinoshita, T., Kanou, H., and Itakura, H., "Development of a single-handed hydrofoil sailing catamaran," Journal of Marine Science and Technology, Vol. 6, pp. 31-41 (2001).

13. Kim, S. H. and Yamato, H., "An experimental study of the longitudinal motion control of a fully submerged hydrofoil model in following seas," Ocean Engineering, Vol. 31, pp. 523-537 (2004).

14. Lai, C. and Troesch, A. W., "A vortex lattice method for high speed planning," International Journal of Numerical Method in Fluids, Vol. 22, pp. 495-513 (1996).

15. Saito, Y. and Ikebuchi, T., "Fully submerged hydrofoil craft. Prediction of Seakeeping Qualities of High-Speed Craft," Proceeding of the Seventh Marine Dynamincs Symposium, pp. 107-141 (1990).

16. Saito, Y. and Kuroi, A., "Active control system of hydrofoils. Control of Marine Vehicles," Proceeding of the Sixth Marine Dynamics Symposium, pp. 75-94 (1989).

17. Savander, B., Scorpio, S., and Taylor, R., "Steady hydrodynamic analysis of planing surfaces," Journal of Ship Research, Vol. 46, pp. 248-279 (2002).

18. Savitsky, D., "Hydrodynamic design of planing hulls," Journal of Marine Technology, Vol. 1, pp. 71-95 (1964).

19. Savitsky, D., DeLorme, M. F., and Raju, D., "Inclusion of whisker spray drag in performance prediction method for high-speed planing hulls," Journal of Marine Technology, Vol. 44, pp. 35-56 (2007).

20. Wang, X., Day, H., and Alexander, A., "Numerical instability in linearized planing problems," International Journal of Numerical Methods Engineering, Vol. 70, pp. 840-875 (2007).

21. Weist, W. R. and Mitchell, W. I., "The automatic control system for the Boeing commercial JETFOIL," IEEE National Aerospace and Electronics Conference, Dayton, Ohio, pp. 366-375 (1976).

22. Xie, N., Vassalos, D., and Jasionowski, A., "A study of hydrodynamics of three-dimensional planing surface," Journal of Ocean Engineering, Vol. 32, pp. 1539-1555 (2005).

23. Yang, S. L. and Chen, S. L., "Experiment and numerical study on gliding-hydrofoil craft rapidity," Proceeding of International Offshore and Polar Engineering Conference, Vancouver, Canada, pp. 375-380 (2008).

24. Yang, S. L. and Gao, L., "Resistance study on full-scale gliding-hydrofoil craft with V-shape planing bottom and TV-shape hydrofoil," Journal of Jiangsu University of Science and Technology: Natural Science Edition, Vol. 4, pp. 16-23 (2006).

25. Yang, S. L., Ma, Q. L., Chen S. L., Gao, L., and Wu, A, "Experimental research on resistance performance of gliding-hydrofoil craft with a T-formed hydrofoil and shallow V-shaped bottom," Online Journal of International Conference on Computational \& Experimental Engineering and Sciences, Vol. 5, pp. 7-14 (2008).

26. Zhou, Z. Q., A Theory and Analysis of Planing Catamarans in Calm and Rough Water, Ph.D. Thesis, School of Naval Architecture and Marine Engineering, University of New Orleans, Louisiana, US (2003). 